\title{
El neuromarketing en la actualidad, ventajas e influencia en los consumidores
}

\section{Neuromarketing today, advantages and influence on consumers}

Clarkent Rubén Mackay Castro

Universidad de Guayaquil

ruben.mackayc@ug.edu.ec

2 Teodoro Mauricio Escalante Bourne

Universidad de Guayaquil

teodoro.escalantebo@ug.edu.ec

3 Rubén Alberto Mackay Véliz

Instituto Técnico Bolivariano

rmackay@itb.edu.ec

$4 \quad$ Teodoro Antonio Escalante Ramírez

Universidad de Guayaquil

teodoro.escalanter@ug.edu.ec
iD https://orcid.org/0000-0002-2657-2168

iD https://orcid.org/0000-0001-9351-4286

https://orcid.org/0000-0001-9272-3991

https://orcid.org/0000-0002-3682-3098

Artículo de Investigación Científica y Tecnológica

Enviado: $18 / 12 / 2021$

Revisado: 29/12/2021

Aceptado: 28//01/2022

Publicado:05/02/2022

DOI: https://doi.org/10.33262/ap.v4i1.1.150

Mackay Castro, C. R., Escalante Bourne, T. M., Mackay Véliz, R. A., \& Escalante Ramírez, T. A. (2022). El neuromarketing en la actualidad, ventajas e influencia en los Cítese: $\quad$ consumidores. AlfaPublicaciones, 4(1.1), 133-149. https://doi.org/10.33262/ap.v4i1.1.150

ALFA PUBLICACIONES, es una Revista Multidisciplinar, Trimestral, que se publicará en soporte electrónico tiene como misión contribuir a la formación de profesionales competentes con visión humanística y crítica que sean capaces de exponer sus resultados investigativos y científicos en la misma medida que se promueva mediante su intervención cambios positivos en la sociedad. https://alfapublicaciones.com 
Palabras

claves:

marketing, neuromarketing, publicidad, marca.

\section{Keywords: \\ marketing, neuromarketing, advertising, branding.}

\section{Resumen}

El uso del Neuromarketing vino a marcar un antes y un después en el mundo del marketing, pasando de técnicas tradicionales para saber las preferencias de los consumidores, a técnicas que permite a través de herramientas tecnológicas identificar diferentes estímulos, obtener información sobre las conductas de los usuarios o consumidores antes, durante y luego de adquirir el producto o servicio, con ello garantizar la apropiación y fidelidad de la marca. Es por esta razón que surge la necesidad de analizar con esta información, los ítems más relevantes sobre el Neuromarketing, así como las ventajas, su impacto en el consumidor, las herramientas tecnológicas usadas e inclusive visualizar hacia donde lleva esta herramienta. La metodología utilizada se basa en un diseño bibliográfico de tipo documental, a través de la cual se realiza una revisión de artículos científicos para una vez obtenida la aproximación epistemológica a través de dichas fuentes, concluir que, las organizaciones deben mantenerse actualizadas con respecto a las técnicas que ofrece el Neuromarketing a fin de permanecer en el tope de la publicidad.

\section{Abstract}

The use of Neuromarketing came to mark a before and after in the world of marketing, moving from traditional techniques to know the preferences of consumers, to techniques that allow, through technological tools, to identify different stimuli, obtain information about the behaviors of the users or consumers before, during and after acquiring the product or service, thereby guaranteeing the appropriation and loyalty of the brand. It is for this reason that the need arises to analyze with this information, the most relevant items about Neuromarketing as well as the advantages, its impact on the consumer, the technological tools used and even visualize where this tool leads. The methodology used is based on a bibliographic design of a documentary type, through which a review of scientific articles is carried out, once the epistemological approach is obtained through these sources, to conclude that organizations must keep updated with respect to the techniques offered by Neuromarketing in order to stay on top of advertising. 


\section{Introducción}

A lo largo del tiempo las organizaciones han mantenido una constante lucha para hacer de sus negocios un imperio, pero para ello por supuesto depende de los consumidores de sus productos, porque buscan hacerse de las mejores técnicas, metodologías, tecnologías, etc., que les permitan mantenerse en la cima del mundo del consumidor.

En ese sentido afirma Santillan \& Peralta (2018), que el desarrollo de las nuevas tecnologías y la importancia en la vida de las personas va en aumento, y esto ha llevado a la creación de nuevos modelos de negocio que buscan seguir atrayendo e interesando de forma diferente e innovadora a los consumidores.

En ese orden de ideas, ante la realidad de un mundo globalizado e interconectado cada vez más, ya los métodos tradicionales, como las promociones y ofertas o descuentos, así como la publicidad convencional, están quedando obsoletos, resultando para el consumidor aburrido lo que conlleva a pocas ventas en aquellas organizaciones que aún se niega a actualizarse. Es por ello que resulta según Palacios et al. (2020), trascendental considerar siempre que un producto o servicio debe ser realmente atrayente para poder ser elegido por el consumidor, puesto que éstos tienen diferentes conductas a la hora de realizar la compra.

Ante lo mencionado, los publicistas tienen que mantenerse atentos sobre la forma en la que basan sus decisiones estos individuos para poder direccionar adecuadamente sus estrategias de comunicación con el fin de promover una acción positiva hacia la marca (Palacios et al., 2020). Y luego agrega el mismo autor que se debe intentar concebir lo que le acontece al usuario en el instante que recibe algún estímulo, pudiendo ser estos: visuales, auditivos, olfativos o sensoriales, ya que la actualidad en la que estamos sumergidos, la cantidad de información que recibe el consumidor es muy grande y además la remembranza de la marca es fundamental.

A la luz de esta realidad, las organizaciones deben apostar a un cambio en sus estrategias de publicidad y una de las mejores estrategias actualmente es el neuromarketing desde donde se entender lo que pasa por la mente del consumidor al momento de decidir que marca o modelo elegir, logrando con ello la fidelización de los clientes en esa marca.

Matías (2019) considera que el neuromarketing, es una disciplina que va a beneficiar notablemente la eficiencia de las empresas de publicidad, puesto que permite a la marca evaluar de manera más precisa las necesidades de los consumidores y realizar un plan estratégico conforme a la información obtenida. Además, las empresas pueden conocer la imagen y emociones que desprende su marca y a partir de ahí, poder elaborar una estrategia de branding más eficiente. Es decir, la importancia del Neuromarketing radica en la posibilidad de entender aquello que sucede en la mente del consumidor en el 
momento de concretar una compra a través de la identificación de los estímulos, pudiendo llegar a hacer una predicción de la conducta de los clientes, ya que comprende qué cambios se producen en los procesos cerebrales al tomar una decisión de compra (Palacios et al. 2020).

Con base en todo lo indicado, desde esta investigación se pretende indagar sobre los fundamentos del Neuromarking, así como sus ventajas e influencias en los consumidores.

\section{Metodología}

Esta investigación se realiza a través de una metodología documental, basada en la revisión de artículos de diferentes autores, la investigación documental es aquella que se realiza a través de la consulta de documentos (libros, revistas, periódicos, memorias, anuarios, registros, códices, constituciones, etc.).

En ese orden de ideas, en este proceso de búsqueda, recuperación, análisis, e interpretación de datos registrados por otros investigadores en fuentes documentales, nos permitió tener una visión más amplia y conceptualizada de los aspectos que tienen que ver con el Neuromarketing para las organizaciones, y con esto poder construir las argumentaciones críticas y validas que permitan establecer la adopción o no de la misma en las empresas.

\section{Resultados y Discusión}

En el proceso de la revisión bibliográfica, se pudo observar que los diferentes autores coinciden desde sus perspectivas en algunas aserciones con respecto al neuromarketing, en lo que respecta a sus opiniones sobre la aplicación en el campo de conocimiento, a las diferentes dimensiones del mundo corporativo, y a las reacciones del consumidor frente a los estímulos, la industria y la forma de transmisión de los mensajes. Todo esto permitió desglosar la investigación en los aspectos que se presentan a continuación.

\section{El Neuromarketimg}

Para Palacios et al. (2020), el neuromarketing es una herramienta de investigación de mercados utilizada por las empresas para conocer el comportamiento del cerebro frente a diferentes estímulos presentados a los consumidores. Es aplicada a través de las emociones, sensaciones y sentimientos que son agradables a los consumidores, ayudando a las empresas a fidelizar y posicionarse en la mente de los consumidores.

Por su parte Escobar (2020), define el neuromarketing como el estudio del funcionamiento del cerebro y su relación e influencia en las decisiones de adquirir bienes o servicios por parte de los usuarios. Esta es una rama del marketing que investiga la respuesta cerebral a los estímulos publicitarios, de marca y de otro tipo de mensajes culturales a los que es expuesto el usuario. 
Santillan \& Peralta, (2018), indican que el Neuromarketing es una estrategia más del Marketing que nos ayuda a conocer cómo se siente un consumidor cuando recibe información, cómo interactúa, qué emociones son las que les incita a comprar y qué colores, diseños y formas atraen su atención. El neuromarketing, es una herramienta diseñada para entender las decisiones de las personas. Su objetivo es conocer y comprender los niveles de atención que muestran las personas a diferentes estímulos. De esta manera se trata de explicar el comportamiento de las personas desde la base de su actividad neuronal (Munarriz, 2018).

En pocas palabras, el neuromarketing es una estrategia fundamental en la actualidad para el marketing, ya que permite a través del estudio del cerebro humano, entender el comportamiento, los sentimientos y emociones del consumidor con respecto a un determinado producto o servicio, con ello poder garantizar el éxito de una marca, y la fidelidad del usuario a la misma.

El neuromarketing surge para explicar el comportamiento del consumidor con ayuda de técnicas científicas, mediante el estudio del proceso de compra, y más aún, el estudio del proceso de la toma de decisiones de los consumidores o posibles consumidores antes de comprar, mientras están comprando y, por supuesto, después de la compra (Santillán \& Peralta, 2018).

Es por ello que el neuromarketing, según Palacios et al. (2020), nace de la fusión entre las neurociencias y la neuropsicología. Esta ciencia explica la razón del por qué y cómo el ser humano tiene comportamientos sensoriales y neuronales que se clasifican y distribuyen de acuerdo con los estímulos exteriores interiores que recibe el individuo. Es así, como el neuromarketing, tiene como base el estudio del cerebro, indica Luco (2018), que este se fundamenta en la teoría del cerebro triple postulada por Paul Maclean, donde se afirma que el cerebro está dividido en 3 áreas diferenciadas por el desarrollo evolutivo del hombre las cuales se describen a continuación:

Cerebro reptiliano. Es el más primitivo y el encargado de nuestra supervivencia, controla todos los procesos inconscientes (bombeo del corazón, digestión, entre otras.).

Sistema límbico. Su función es la encargada de procesar nuestras emociones y sentimientos (alegrías, tristezas, entre otras).

El neocórtex. Es la zona más evolucionada de nuestra mente. Es el encargado de todas las habilidades superiores como la lógica, los pensamientos conscientes y las matemáticas, entre otras.

Ahora bien, de acuerdo a las investigaciones realizadas el cerebro que se activa al momento de tomar decisiones para las compras es el sistema reptiliano, para Luco (2018), "las compras afectan a la supervivencia del individuo y allí, entra de lleno el 
cerebro reptiliano". Es decir, las compras de una u otra manera son parte de la forma de sobrevivir en cuanto a comida, vestido, comodidades, servicios, etc. se refiere y es allí donde el cerebro reptiliano actúa.

Asimismo, indica Palacios et al. (2020), el cerebro reptiliano o primitivo como también se le denomina, solo considera aquello relacionado con su bienestar, además, el cerebro primitivo tiene una corta capacidad de atención, lo que le permite sólo recordar el principio y el final, también es visual, lo que hacer que tenga un vínculo efectivo con el verdadero decisor. Finalmente tiene un estímulo de reacción instantánea con respecto a la emoción.

Ante esta realidad, al momento de diseñar una publicidad, se deben considerar las características mencionadas del cerebro primitivo, para garantizar la conexión entre el producto y el consumidor. Es ello, que según Palacios et al. (2020) el Neuromarketing tiene los siguientes objetivos

- Conocer el sistema nervioso, descodificando los estímulos recibidos al lenguaje del cerebro.

- Anticipar a la conducta que seguirá el usuario a la hora de consumir. Para que esto funcione se intenta elegir el formato de comunicación que mejor recuerde el consumidor.

- Desarrollar todos los aspectos del marketing: comunicación, producto, precios, Branding, posicionamiento, targeting, planeamiento estratégico, canales de distribución etc., seleccionando los mensajes que mejor y más rápido llegaran al consumidor, dependiendo de las características que tenga el producto y a quien va dirigido.

- Percibir y cumplir de la mayor manera posible sus expectativas que tenga el cliente sobre un producto en cuestión.

De esta manera Soto \& Acero (2016) mencionan que:

"El Neuromarketing tiene como objetivo fundamental permitir a las empresas recopilar información lo suficientemente pertinente para comprender las verdaderas necesidades de los clientes, con el fin de establecer estrategias, técnicas y tecnologías para ubicar los productos y servicios en su mente, sus intereses, sus bolsillos, sus hogares y sus actividades".

\section{Tipos de Neuromarketing}

Los tipos de Neuromarketing se dividen según Palacios et al. (2020), en tres de acuerdo a los sentidos, estos son: 
- Neuromarketing auditivo: Se refiere a lo que se percibe a través del sentido de audición, es todo aquello que escuchamos. Se toman en cuenta elementos como tonos, ritmos, intensidades, volúmenes, entre otros. Acá se deben tomar en cuenta lo que se dice o se escucha en los anuncios radiales y televisivos, es decir se debe escoger con sumo cuidado a fin de generar una relación muy cercana con los consumidores que usan este medio.

- $\quad$ Neuromarketing visual: Se refiere a lo que se percibe por el sentido de la visión, es todo lo que se capta con la vista. Acá, se toma en cuenta elementos como la luz, el color, la imagen, el diseño, mismos que son aprovechados en la creación de productos o publicidades.

- Neuromarketing Kinestésico: Se refiere a lo que se percibe a través de los sentidos del tacto, el olfato y el gusto, este tipo de (2016 complementa los otros dos tipos.

Es así como se pone en juego todos nuestros sentidos y es a través de la mente que ellos procesan nuestras decisiones, afirma Palacios et at. (2020) que, "el Neuromarketing se ha denominado la llave de nuestra lógica para la compra: los pensamientos, sentimientos y deseos subconscientes que mueven las decisiones de compra que se toman todos los días de la vida". Es por ello encontramos en muchas campañas publicitarias algunas técnicas o estrategias enmarcadas a despertar esas sensaciones.

\section{Ventajas}

Algunas de las ventajas que presenta el Neuromarketing para las organizaciones las desglosa Palacios et al. (2020) son las mostradas en la tabla 1.

\section{Tabla 1}

\section{Ventajas del Neuromarketing}

\begin{tabular}{l}
\hline Ventajas del Neuromarketing \\
\hline Los resultados de los estudios de Neuromarketing son más acertados que los resultados de \\
estudios de otros tipos de marketing. Esto es debido a que las herramientas y técnicas \\
utilizadas son fisiológicas y de forma inconsciente. Además, se puede medir los estímulos \\
sin tener que hacer preguntas al consumidor. \\
\hline El Neuromarketing permite evaluar de manera precisa lo que el consumidor siente y \\
piensa. Con ello se garantiza que actitud tomara ante una reacción de manera consciente o \\
inconsciente. Es decir, al conocer esas reacciones se puede condicionar para que actué \\
como se quiere que lo haga. \\
\hline El Neuromarketing nos permite optimizar las técnicas publicitarias de las campañas para \\
llamar la atención del consumidor. \\
Los datos proporcionados por el Neuromarketing son bastante más tangibles que los del \\
marketing tradicional. Permitiendo saber con más precisión las necesidades reales de los \\
consumidores.
\end{tabular}

Fuente: Palacios et al. (2020) 
Por su parte Munarriz (2018) considera las siguientes ventajas del neuromarketing: mensajes más efectivos (sencillos y claros), optimizar recursos, se ajustan al tiempo de las personas, se centra en las personas no en producto (como entiende el consumidor el mensaje).

Con base a lo planteado por los autores anteriores, y viendo los puntos de coincidencia es importante resaltar que, en los actuales momentos, las organizaciones deben aprovechar todas estas ventajas, haciendo uso del resultados obtenidos y planteados del neuromarketing, para sus campañas publicitarias, con ello garantizar que los usuarios se apropien de la marca y puedan mantenerse en el tiempo como consumidores de sus productos aplicando el concepto de fidelidad. Sin embargo, siempre hay que ser objetivo al plantearse un cambio en la organización, en este caso con respecto a la implementación del neoromarketing se debe considerar de acuerdo a la empresa (su tamaño, posición económica, empleados, etc.), cuáles serán las estrategias y técnicas a considerar en el tiempo, a fin de no causar un desequilibrio en perjuicio de la empresa.

En ese sentido una limitante que se puede presentar en especial en las organizaciones tradicionales es el miedo al cambio, pensar que la empresa como está, está bien. O puede surgir el efecto contrario y hacer grandes inversiones en estrategias que involucran costo de equipos y personal. Indican Botello \& Suárez (2018), debido a la especialización de los equipos que se requieren y del personal capacitado para la lectura de resultados de los estudios, se constituye en un costo elevado para aquellas empresas que no disponen de recurso económico, destinado a la investigación y desarrollo. Entonces, son las multinacionales y conglomerados empresariales, quienes pueden financiar este tipo de estudios.

Aunado a lo anterior, Soto \& Acero (2016) señala otras limitantes como son las mostradas en la tabla 2.

\section{Tabla 2}

\section{Limitantes del neuromarketing}

\begin{tabular}{ll}
\hline Limitantes & Definición \\
\hline \multirow{2}{*}{ Tamaño de la muestra } & $\begin{array}{l}\text { No muchas personas están dispuestas a que su } \\
\text { cerebro sea leído y escaneado, por lo cual es muy } \\
\text { difícil tener grandes muestras a diferencias de las } \\
\text { encuestas o los focus group }\end{array}$ \\
\hline & $\begin{array}{l}\text { Alrededor del neuromarketing se han tejido teorías } \\
\text { de que estas investigaciones podrán ser usadas para } \\
\text { Mala imagen }\end{array}$ \\
& $\begin{array}{l}\text { mealizar publicidad subliminal o para controlar la } \\
\text { de decisión }\end{array}$ \\
\hline
\end{tabular}

Fuente: Soto \& Acero (2016) 
A pesar de estas desventajas, el mundo del neuromarketing sigue creciendo y sigue haciendo avances en sus investigaciones, tomando como retos estas limitantes, por los momentos las empresas deben buscar un equilibrio y considerar los pros y los contras de determinadas técnicas o estrategias, para una determinada organización.

\section{Tecnologías empleadas}

Algunos autores de esta revisión documental como Palacios et al. (2020) y Matías (2019) entre otras coinciden en el uso de técnicas usadas en las investigaciones y trabajos del neuromarketing como las mostradas en la tabla 3.

\section{Tabla 3}

\section{Técnicas usadas en el Neuromarketing}

\begin{tabular}{|c|c|}
\hline Técnica & Descripción \\
\hline $\begin{array}{l}\text { Resonancia } \\
\text { (FMRI) }\end{array}$ & $\begin{array}{l}\text { Es una técnica que permite monitorear funciones de regiones } \\
\text { responsables de la sensorialidad, motricidad, cognición y } \\
\text { procesos afectivos. Permite obtener imágenes del cerebro } \\
\text { mientras se realiza una actividad concreta y siendo necesario } \\
\text { para ello, un equipo humano multidisciplinario de expertos } \\
\text { en diversas disciplinas. Es costosa, pero genera resultados } \\
\text { muy completos y confiables. }\end{array}$ \\
\hline Encefalografía (EEG). & $\begin{array}{l}\text { Analiza los cambios en los impulsos eléctricos del cerebro } \\
\text { también de acuerdo a los estímulos recibidos a través de } \\
\text { varios electrodos que se conectan a la cabeza. A partir de las } \\
\text { imágenes obtenidas, se puede identificar la respuesta } \\
\text { emocional de una persona frente a un producto. }\end{array}$ \\
\hline Magneto Encefalografía (MEG). & $\begin{array}{l}\text { Mide los cambios magnéticos que se producen en el cerebro } \\
\text { por la actividad coordinada de las neuronas ante estímulos } \\
\text { concretos. Es decir, permite definir la actividad cerebral a } \\
\text { tiempo real, ubica las activaciones cerebrales con una } \\
\text { resolución espacial de milímetros, es sensible a cambios } \\
\text { leves de la actividad cerebral. }\end{array}$ \\
\hline Tomografía (PET). & $\begin{array}{l}\text { Mide los cambios en el metabolismo del cerebro. } \\
\text { Concretamente, mide la dispersión espacial de un } \\
\text { radioisótopo administrado al sujeto analizado a través de una } \\
\text { inyección }\end{array}$ \\
\hline Biofeedback & $\begin{array}{l}\text { Permiten que un sujeto, mediante instrumentos electrónicos } \\
\text { que generan señales auditivas o visuales, tenga consciencia } \\
\text { de cambios fisiológicos y biológicos que normalmente no son } \\
\text { conscientes (ritmo cardíaco, presión arterial, conductancia de } \\
\text { la piel, velocidad del pulso, etc.) Con estas técnicas el } \\
\text { paciente puede modificar sus propios estados orgánicos y } \\
\text { provocar su normal funcionamiento. }\end{array}$ \\
\hline
\end{tabular}




\section{Tabla 3}

Técnicas usadas en el Neuromarketing (continuación)

\begin{tabular}{ll}
\hline Técnica & Descripción \\
\hline & Mide el ritmo cardiaco. El latido del corazón normalmente se \\
& mide en términos de tiempo entre latidos y se ha descubierto \\
& que las deceleraciones en el corto plazo suelen estar \\
& relacionadas con el incremento de la atención, a la vez que \\
Ritmo cardiaco & las aceleraciones a más largo plazo suelen corresponderse \\
& con alguna excitación emocional negativa (respuesta \\
& defensiva). Pero, no ofrece información suficiente para saber \\
& de qué tipo de emoción se trata.
\end{tabular}

Esta técnica analiza básicamente el movimiento de los ojos al observar imágenes que cambian a gran velocidad, así las personas estudiadas de manera inconsciente reaccionan ante

Seguimiento ocular o Eye Tracking las imágenes que más les generan impacto durante el experimento. Se caracteriza por ser una tecnología accesible, de bajo coste y por su facilidad para transportarla.

Los cambios en la resistencia galvánica de la piel dependen de ciertos tipos de glándulas sudoríparas que son abundantes

Respuesta galvánica de la piel. en las manos y los dedos. Detecta los diferentes cambios en la actividad eléctrica de la piel que pueden deberse al miedo, ira o a deseos sexuales ante un estímulo. Es de bajo costo.

Es una técnica médica que consiste en la aplicación de pequeños electrodos de bajo voltaje en forma de agujas en el territorio muscular que se desea estudiar para medir la respuesta y la conectividad entre los diferentes electrodos. Se

Electromiografía (EMG). utiliza para registrar micro expresiones faciales que están conectadas directamente con estados emocionales. Cuando somos sometidos a un estímulo (por ejemplo, un anuncio de televisión), los músculos de nuestra cara se mueven involuntariamente como reacción a lo que estamos viendo. Analiza profundamente las respuestas sensoriales a los

Marketing Olfativo estímulos recibidos, en este caso el olfato que resulta ser el más sensible entre todos los demás sentidos

Fuente: Palacios et al. (2020) y Matías (2019)

\section{Influencia en los consumidores}

$\mathrm{Al}$ estar el neuromarketing basado en estudios de la mente de los consumidores, es evidente que marca una gran influencia, otorgándole a este, lo que piensa y siente en el producto; ya los publicitas y diseñadores no necesitan adivinar o suponer como tradicionalmente se hacía, al realizar una campaña, debido a que el neuromarketing identifica los patrones de respuesta causa y efecto garantizando con ello mayor posibilidad de consumo y fidelidad en una determinada marca, que es en si el objetivo principal de las empresas. 
El neuromarketing proporciona conocimiento sobre el comportamiento del cliente frente al producto o servicio, también hace referencia a diferentes aspectos que rodean al cliente o consumidor en cuanto a cultura, raza, educación, economía, religión, política, factores neurales, familia, etc., estos aspectos son muy importantes para el neuromarketing ya que estos influyen en la manera como el cliente y/o consumidor puede llegar a relacionar los productos, y de la manera como estos perciben dicho producto que conlleva a que estos puedan llegar a adquirirlo (Soto \& Acero, 2016).

Es así, como el neuromarketing difunde algunas estrategias, a fin de influir en la conducta del consumidor, Luco (2018) las presenta como sigue:

- Uso de imágenes: es una de las mejores herramientas para que el cliente tome decisiones de compra. Las imágenes ayudan a estimular el cerebro reptiliano. Se usa como apoyo un folleto, un tríptico e incluso un dibujo mientras se conversa con el cliente.

- Tutear al cliente: Usar la segunda persona dado que el cerebro reptiliano del cliente se activa cuando se usa el 'tú', lo cual facilita las acciones de venta. Inclusive identificarlo con su nombre ya que esto permite establecer una conexión emocional con él y que se sienta más a gusto.

- Utilizar el número 3: los estudios demuestran, hasta un máximo de tres (3) opciones de compra al cliente. Cuando es mayor según dichos estudios el cerebro empieza a saturarse.

- Mensaje claro: utilizar un discurso concreto, sin abstracciones ni complejidades. Esto hace que el área cerebral que toma las decisiones de compra entienda con mayor facilidad.

- Hacer uso de discurso de contrataste o diferencias para que la parte inconsciente del ente del cliente comprenda y decida a comprar. Por ejemplo: antes, ahora; mucho, poco.

\section{Tendencia en las redes sociales}

Las redes sociales han permitido crear espacios publicitarios virtuales con características muy apropiadas de marketing, ampliando la gestión de contenidos eficaces, a través de diseños llamativos, sonidos acordes a la publicidad, buen uso de colores entre otros, más, sin embargo, muchas veces, esta publicidad se pierde en el espacio cibernético porque no llena al usuario.

Indica Escobar (2020), si la empresa tiene poca presencia en los canales publicitarios se puede aprovechar los medios digitales, incentivar la lealtad, generar experiencias memorables para los clientes, rediseñarlos empaques o apoyarse en las emociones. En la 
historia se ha visto cómo grandes multinacionales que no se han adaptado a los cambios que ofrece el marketing se han ido a la quiebra.

A la luz de esa realidad, nace la imperiosa necesidad de hacer uso del neuromarketing como herramienta estratégica que permite anticipar y medir las percepciones del internauta ayudando así a crear contenidos exitosos que alcancen la parte emotiva del cerebro, y resulten en la aceptación del producto o servicio (Palacios et al., 2020).

Es decir, en el mundo publicitario actual, si se quiere tener éxito con una determinad marca se debe hacer uso de las estrategias de neuromarketing para anticipar lo que desean los usuarios y de las redes sociales para conectar con mayor alcance a las marcas con el segmento de usuarios apropiado, además de permite generar viralización que significa, el replicar el mensaje a más y más personas.

Otra característica importante del neuromarketing en las redes sociales es la reducción del miedo a pagar. Indica Martin (2018) mencionado por Santillán \& Peralta (2018) que, según los últimos estudios de neuromarketing digital, la idea de pagar crea ansiedad en los usuarios. Por eso, es más efectivo sustituir la palabra "comprar" por otras opciones más neutras como "añadir al carrito".

Luego es importante resaltar que, para hacer uso de las estrategias de neuromarketing a través de internet, se debe considerar algunos aspectos derivados del uso de la conectividad virtual, estas son la inmediatez de respuesta que se obtiene, uso de imágenes llamativas, música agradable de acuerdo al tipo de consumidor que se quiere llegar entre otros.

Provocar emociones es transcendental en todo ámbito, ya que, al utilizar sonidos o imágenes en el mensaje publicitario, hace que se aviva la parte del cerebro reptil, ocasionando empatía con el usuario. Es así como mediante la aplicación del neuromarketing se ha podido crear campañas publicitarias adecuadas para cada target, alcanzando un mayor impacto y recordación del mensaje (Baraybar et al. 2017).

\section{Tendencias del Neuromarketing}

En un mundo tan acelerado y cambiante como el actual, es evidente que los consumidores $\mathrm{y}$ vendedores tratan de llevar ese ritmo cambiante y transformarlo en beneficios y comodidades, es por ello que el neuromarketing no ha dejado de crecer, de actualizarse, de hacer nuevas investigaciones, dando inicio a nuevas tendencias como son:

- Nanomarketing: Permite integrar herramientas de medición de neuromarketing en pequeños dispositivos no intrusivos e inalámbricos, como es el caso de las pulseras inteligentes. Con estos dispositivos, podemos alcanzar un mayor entendimiento de las emociones del consumidor y sus comportamientos. 
Además, indica Melgar (2018), no serían tan intrusivos y el sujeto no estaría tan condicionado, también supone la creación de aparatos multifuncionales integrando propiedades de distintas técnicas ya existentes, por ejemplo, podría medir simultáneamente, el ritmo cardiaco, la sudoración de la piel, entre otras.

- Hiperpersonalización: Trata de resaltar a través de los estudios e investigaciones del neuromarketing la alta influencia de las emociones en los consumidores, por ello se apunta cada vez más a las experiencias altamente personalizadas (Acumbamail, 2021)

Es decir, con las técnicas y medios adecuados, la empresa desarrolla servicios de atención al cliente más personalizados, como por ejemplo empleo de lenguajes acorde al cliente, hacer demostraciones personalizadas como es el producto o servicio ofrecido por la marca y aún más allá ofrecer beneficios y ayudas post compra al consumidor.

- El aprendizaje automático: Es una rama de la inteligencia artificial que permite el estudio del aprendizaje automático de sistemas, a través de los datos y la identificación de patrones de comportamiento humano para posteriormente, tomar decisiones sin ningún tipo de intervención humana.

Esta disciplina permitirá analizar infinidad de datos complejos de forma precisa y rápida, ya que actualmente, al haber tanta información, analizarla manualmente es difícil y, por tanto, es necesario confiar en algoritmos para el procesamiento y análisis de los datos (Matías, 2019).

- Internet de las cosas: el IoT (Internet of Things) es una herramienta que lleva el internet a otro nivel, siendo usado para automatizar cosas, casas, hospitales y hasta ciudades, afirma Matías (2019), en poco tiempo se prevé que la mayoría de los electrodomésticos sean inteligentes

Lo anterior, le permite al neuromarketing, medir y monitorear el comportamiento de las personas al hacer uso del IoT.

- La realidad aumentada y realidad virtual: Este tipo de tecnología permite la optimización de los estudios sobre el comportamiento del consumidor pues complementa a las técnicas de neuroimagen ya existentes, así lo indica Ruiz, mencionado por Matías (2019), "la realidad aumentada agrega elementos digitales a una vista en vivo, por medio de dispositivos inteligentes, mientras que la realidad virtual implica una experiencia de inmersión completa donde los usuarios puedes ser transportados a diversos entornos reales e interactuar con ellos". 
Con base a lo anterior, estas herramientas tecnológicas permitirán disminuir las experiencias en laboratorios para validar el comportamiento humano ante un determinado producto, ya que permitirá que el consumidor se transporte de una manera más divertida y sencilla a un determinado contexto y ver sus reacciones conductuales. Indica Matías (2019) que, además, supone un ahorro tanto en costes como en tiempo pues no hay necesidad de desplazarse para probar distintos escenarios.

- Biometría integrada: Esta tecnología incorpora al cuerpo humano dispositivos, actualmente es más utilizado en la medicina, permitiendo obtener información a través de los mismo del paciente. Por ejemplo, dispositivo para monitorear pulsaciones cardiacas y vasos sanguíneos, neuro estimuladores, entre otros.

Como se observa, la evolución del neuromarketing pasa por analizar y probar nuevas estrategias que nos ayuden a entender mejor a los consumidores $\mathrm{y}$, de esta forma, poder elaborar estrategias de marketing más efectivas.

\section{Conclusiones}

Es indudable que el neuromarketig llegó para quedarse como estrategia del marketing, al ser una herramienta que estudia el comportamiento humano, permite tener una amplia posibilidad de garantizar que los consumidores o usuarios opten por una determinada marca o servicio y mantengan su fidelidad con la misma a lo largo del tiempo, mientras se le siga aplicando las condiciones que le hicieron decidirse por ella, y es en este punto donde nace la competencia entre las marcas.

Siendo lo anterior, lo que precisamente ha hecho que el neuromarketing siga gestionando más y más investigaciones y ponga a sus servicios toda una gama de herramientas tecnológicas, a fin de conocer en profundidad mayor el cerebro y el comportamiento humano, por eso el tema del neuromarketing seguirá revolucionando el marketing para las organizaciones. Indica Botello \& Suárez (2018), "La tendencia en la implementación de los principios de neuromarketing, es ascendente"

Además, el neuromarketing trae consigo un conjunto de recursos de enorme valor para investigar el mercado, segmentarlo y desarrollar estrategias exitosas en materia de productos (diseño, marca, packaging), posicionamiento, precios, comunicaciones y canales (Santillán \& Peralta, 2018)

Sin embargo, en esta investigación documental, se buscó conjugar algunas aserciones iniciales de los autores sobre neuromarketing, a fin conocer dónde estamos y hacia dónde vamos en el neuromarketing, esto permitió discernir las siguientes conclusiones:

- El neuromarketing es una herramienta del marketing, que permite con investigaciones muy confiables conocer las conductas de los usuarios en 
referencia a sus estados de ánimo, gustos, preferencias de un determinado producto o servicio.

- Gracias a estas técnicas de neuromarketing, podemos analizar el comportamiento de los consumidores con mayor precisión ya que complementan a las técnicas tradicionales de marketing, reduciendo así el margen de error de los estudios de mercado y permitiendo satisfacer las necesidades de la sociedad de una forma más eficiente (Matías, 2019).

- Esas necesidades de los clientes se identifican, según Santillan \& Perlata (2018), luego por medio de la publicidad se impacta el comportamiento de compra, generando cambios en la conducta de compra y como el neuromarketing tiene una aplicación al sector retail, permitiendo el análisis sobre los comportamientos y actitudes que los clientes expresan o manifiestan en su experiencia de compra (Santillan \& Peralta, 2018).

- Para Palacios et al. (2020) el neuromarketing mide los estímulos, las emociones, la motivación, los sentimientos de las personas, por medio del estudio de los sistemas neuronales que rigen el cerebro humano con el fin de relacionarlo con la conducta y el comportamiento del consumidor.

- Sin embargo, debido a la especialización de los equipos que se requieren y del personal capacitado para el manejo de los equipos y para la lectura de resultados de los estudios, lo que hace que el costo de los estudios sea elevado para aquellas empresas que no disponen de recurso económico, por lo que, son las multinacionales y conglomerados empresariales, las que pueden financiar este tipo de estudios. Además, muchas veces, los resultados de investigación en el campo son privados y por tanto poco difundidos.

- Con base a lo anterior, sugiere Botello \& Suárez (2018) que, debe generarse un cambio de percepción general del neuromarketing, la construcción de una comunidad fuerte que genere contenido y descubrimientos que, beneficien tanto a las compañías gigantes que tienen el musculo financiero para costearlos, como a las compañías pequeñas que pretendan utilizar la información compartida por los estudios y la adapten a su situación actual para aplicarla.

\section{Referencias Bibliográficas}

Acumbamail. (10 de Mayo de 2021). Tendencias del Neoromarketing en 2021.

Baraybar, A., Baños, M., Barquero, Ó., Goya, R., \& De la Morena, A. (2017). Evaluación de las respuestas emocionales a la publicidad televisiva desde el Neuromarketing. Comunicar , XXV (52), 19-28.

Botello, S., \& Suárez, K. (2018). Tendencias de investigación en neuromarketing. Cuadernos Latinoamericanos de Administración 14(27), 14 (27), 53-90. 
Escobar, T. (2020). El Neuromarketing en el marco del Covid-19. Universidad Católica de Colombia, Facultad de Ciencias Económicas y Administrativas. Bogotá, Colombia: Trabajo especial de grado de la Universidad Católica de Colombia para optar al título de Especialista en administración financiera.

Luco, A. (10 de octubre de 2018). 6 estrategias de neuromarketing para vender a tus clientes.

Matías, A. (2019). Neurociencia aplicada al consumidor. Comillas. Universidad Pontifica. Madrid: Trabajo especial de grado de la Universidad Pontificia Comillas.

Melgar, J. (2018). Nanomarketing ¿El futuro del Neuromarketing?

Munarriz, R. (2018). Neuromarketing. Lima: Seminario Miércoles del Exportador.

Palacios, D., Peña, I., Arias, A., \& Macias, D. (septiembre de 2020). El neuromarketing y su influencia en la publicidad en redes sociales para las MiPymes de ManabíEcuador. Observatorio de la Economía Latinoamericana.

Santillán, F., \& Peralta, J. (2018). Influencia del Neuromarketing y sus beneficios: Caso Helados Below Zero. Universidad Estatal de Milagro. Ecuador, Facultad de Ciencias Administrativas y Comerciales. Milagro, Ecuador: Trabajo especial de grado de la Universidad Estatal de Milagro para optar al título de Ingeniería en Marketing.

Soto, O., \& Acero, F. (2016). El neuromarketing como herramienta administrativa en Colombia. Universidad Pedagógica y Tecnológica de Colombia, Programa de Administración de Empresas. Colombia: Trabajo especial de grado de la Universidad Pedagógica y tecnológica de Colombia para optar al título de Administrador de Empresas.

\section{LCiencia}


El artículo que se publica es de exclusiva responsabilidad de los autores y no necesariamente reflejan el pensamiento de la Revista Alfa Publicaciones.

\section{Ciencia}

El artículo queda en propiedad de la revista y, por tanto, su publicación parcial y/o total en otro medio tiene que ser autorizado por el director de la Revista Alfa Publicaciones.
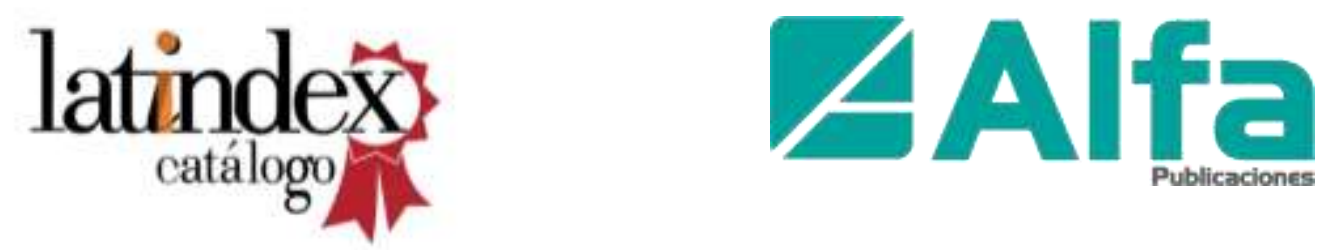

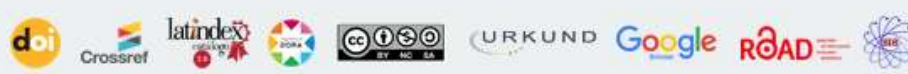
DLatinREV

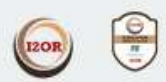

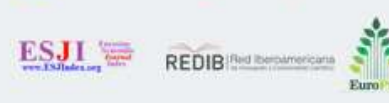

$\underbrace{}_{\text {wizdom.ai }} \mathrm{O}_{\text {OpenAIRE }}^{+}$

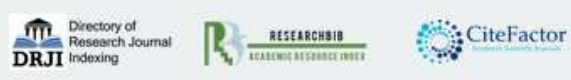

